\title{
CONJUNTO DE INDICADORES DE SUSTENTABILIDADE EMPRESARIAL: UMA PROPOSTA DE AVALIAÇÃO PARA MICRO E PEQUENAS EMPRESAS DO SEGMENTO AGROINDUSTRIAL
}

\author{
Set of Corportate Sustainability Indicators: An Evaluation Proposal for Micro and Small \\ Companies in the Agroindustrial Segment
}

\begin{abstract}
RESUMO
Para mensurar a sustentabilidade dos empreendimentos, ganhou ênfase a utilização de indicadores que, utilizados no planejamento e processo decisório, permitam o acompanhamento e avaliação das organizações em relação à sustentabilidade. Tendo presente que a maioria dos instrumentos de mensuração da sustentabilidade empresarial existentes avaliam empresas de grande porte, o objetivo do presente estudo foi o de identificar um conjunto de indicadores apropriado as micro e pequenas empresas agroindustriais. Metodologicamente foi desenvolvida uma pesquisa em duas etapas, uma exploratória e a outra descritiva, em ambas etapas as fontes do estudo qualitativo e quantitativo foram bibliográficas. O conjunto de indicadores proposto a partir da frequência de repetição foi submetido a avaliação de proprietários de agroindústrias e acadêmicos das áreas de gestão e sustentabilidade com o intuito de avaliar a importância dos indicadores sugeridos na mensuração da sustentabilidade e os aspectos relativos à facilidade na obtenção dos dados necessários à elaboração dos respectivos indicadores. A partir da média dos pesos atribuídos fez-se o cruzamento das informações relativas ao grau de importância e dificuldade dos indicadores em uma matriz específica. Como resultados identificouse que o conjunto proposto está adequado a realidade dos empreendimentos e poderá ser utilizado para mensurar a sustentabilidade de micro e pequenas agroindústrias contribuindo com a sustentabilidade destas organizações.
\end{abstract}

Guilherme Scheuermann

Universidade do Vale do Taquari - UNIVATES

guilhermes@univates.br

Carlos Cândido da Silva Cyrne

Universidade do Vale do Taquari - UNIVATES

cyrne@univates.br

Recebido em: 03/07/2019. Aprovado em: 21/07/2020.

Avaliado pelo sistema double blind review

Avaliador científico: Paulo Henrique Vicente Montagnana Leme

DOI: 10.48142/2238-68902019v21n1-3p7993

\begin{abstract}
In order to measure the sustainability of the enterprises, the use of indicators that, used in planning and decision making was emphasized, allow the monitoring and evaluation of organizations in relation to sustainability. Bearing in mind that most of the existing business sustainability measurement instruments evaluate large companies, the objective of this study was to identify a set of indicators appropriated to micro and small agroindustrial companies. Methodologically the research was developed in two stages, one exploratory and the other descriptive, in both stages the sources of the qualitative and quantitative study were bibliographical. The set of indicators proposed from the repetition frequency was submitted to the evaluation of agroindustry owners and academics from the areas of management and sustainability in order to evaluate the importance of the indicators suggested in the measurement of sustainability and the aspects related to the ease in obtaining the data needed to produce the respective indicators. From the average of theassigned weights, the information on the degree of importance and difficulty of the indicators was cross-referenced in a specific matrix. As results, it was identified that the proposed set is adequate to the reality of the enterprises and could be used to measure the sustainability of micro and small agroindustries contributing to the sustainability of these organizations.
\end{abstract}

Palavras-chave: Desenvolvimento Sustentável. Índice. Responsabilidade Social.

Keywords: Sustainable Development. Index. Social Responsability.

\section{INTRODUÇÃO}

O capitalismo é um modelo econômico que prevê crescimento e lucro por intermédio da transformação dos fatores de produção em bens e serviços. Logo, a geração de resultados financeiros é o principal objetivo da maioria dos empreendimentos. Segundo Marquez (2015), esta é a origem ou a principal causa do colapso ambiental, o fato de o capitalismo ser um sistema que prioriza geração 
de lucro. De acordo com Leff (2007), é necessário que a preocupação com a preservação ambiental supere a racionalidade da teoria econômica atual.

Neste contexto, em que os processos produtivos têm importância significativa na geração de resultados econômicos e no atendimento às demandas da população, conforme destacam Sharma, Chandna e Brardwaj (2017), as organizações estão sendo instigadas a contemplar programas ambientais em seu planejamento. Assim, se intensificou a busca por meios de produção de menor impacto ambiental ou práticas que permitam sua mitigação, levando a um processo dito sustentável, o que requer o envolvimento dos stakeholders, bem com o propósito, a missão, a visão e os valores organizacionais. Deste modo, ao encontro dos estudos desenvolvidos por muitos autores, os princípios de sustentabilidade devem ser incorporados ao longo de toda a cadeia de valor da indústria (KOZLOWSKI, SEARCY, BARDECKI, 2015).

Mensurar os impactos da atividade, sobre a sustentabilidade dos empreendimentos, é importante para que as organizações se tornem competitivas, reduzindo incertezas e garantindo a sobrevivência das organizações diante de um mercado concorrido e incerto, trata-se de um tema complexo e abrangente em virtude da variedade de índices e indicadores desenvolvidos para tal finalidade. As últimas três décadas contam com um aumento significativo no número de empresas que se propõem a medir a sustentabilidade, cada uma com conjuntos diferentes de indicadores (RAHDARI; ROSTAMY, 2015). Mesmo assim, segundo Carrasquer, Uchie e Martínez-Garcia (2017), deve-se considerar os estudos que demostram a importância da utilização de indicadores para gerir melhor os recursos e otimizar processos produtivos.

Para Feil, Quevedo e Schreiber (2015), estes indicadores têm como finalidade simplificar, quantificar, analisar e transmitir informações complexas sobre sustentabilidade de uma forma mais simples. Esta concepção pode ser reafirmada a partir do que conceituam Imperador e Silva (2018), ao definir que as organizações demandam por métodos que viabilizem a elaboração de informações condensadas para utilizar na tomada de decisões complexas.

Feil, Quevedo e Schreiber (2015), destacam que a grande maioria dos esforços realizados até o presente momento tiveram como objetivo principal atender a grandes corporações, deixando de lado as especificidades das micro e pequenas empresas, porém, deve-se alertar para o fato de que a soma dos impactos ambientais causados por estes empreendimentos tende a ser de maior intensidade quando comparados ao impacto causado por grandes corporações.
Quando reflete-se sobre o sistema agroalimentar mundial e as orgnaizações que nele atuam, pode-se afirmar que, em sua maioria produzem e comercializam alimentos processados a partir de cadeias longas de suprimentos (PLOEG, 2008 apud GAZOLA; SCHNEIDER; BRUNORI, 2018). Neste sentido, conforme Lang e Heasman (2009) apud Gazola, Schneider e Brunori (2018), os alimentos comercializados perdem referência quanto ao local ou região na qual foram produzidos e acabam por não considerar aspectos sociais, ambientais e de saúde. Logo, as agroindustrias familiares surgem como alternativas para a produção de orgânicos, demais itens de valor agregado e qualidade diferenciada através de cadeias curtas de comercialização (RENTING, MARSDEN, BANKS, 2003; SCHNEIDER; GAZOLLA, 2015 apud GAZOLA; SCHNEIDER; BRUNORI, 2018)

Assim, a presente pesquisa teve como tema os indicadores de sustentabilidade empresarial, delimitandose ao estudo de sua utilização por micro e pequenas empresas do segmento agroindustrial, localizadas no Vale do Taquari/RS, Brasil. Destaca-se, que os indicadores de sustentabilidade contemplados neste estudo são os que compõem: o Índice de Sustentabilidade Empresarial da B3 (ISE), são utilizados pelo Instituto Ethos de Responsabilidade Social Empresarial (RSE) e fazem parte do Guia de Sustentabilidade da Revista Exame. Sendo assim, presente estudo se propôs a responder ao seguinte questionamento: qual é o conjunto de indicadores de sustentabilidade empresarial mais apropriado as micro e pequenas empresas agroindustriais? Deste modo, o objetivo geral consiste em propor um conjunto de indicadores de sustentabilidade empresarial a ser utilizado por micro e pequenas empresas do segmento agroindustrial.

O presente estudo justifica e demonstra sua relevância ao destacar a responsabilidade socioambiental das organizações empresariais. Além, de conduzir um olhar crítico a este grupo de empresas de atuação regional em sua maioria, e destacar sua importância em relação ao desenvolvimento regional sustentável. Para Mior (2005) apud Gazola, Schneider e Brunori (2018), no caso dos alimentos produzidos pelas agroindústrias familiares, são incorporados os saberes e a cultura regional que, além de outros fatores, proporcionam valor adicionado a estes empreendimentos. Neste sentido, conforme destaca Agostini (2015, p.28), são as características peculiares de cada região "[...] que podem dar conta do desenvolvimento na perspectiva territorial, enfatizando a dinâmica e a diversidade de cada região, e, nessas condições, promover o desenvolvimento regional sustentável". 


\section{REVISÃO BIBLIOGRÁFICA}

Nesta secção são apresentados os conceitos de sustentabilidade e de indicadores de sustentabilidade. Também, são descritos: o Índice de Sustentabilidade Empresarial (ISE), os Indicadores Ethos de Responsabilidade Social Empresarial - RSE e o Guia de Sustentabilidade Revista Exame.

\subsection{Sustentabilidade}

De acordo com Miller e Spoolman (2012, p.5), a sustentabilidade pode ser definida como "[...] a capacidade dos sistemas da terra e dos sistemas culturais humanos de sobreviver, prosperar e se adaptar às mudanças nas condições ambientais no longo prazo". A expressão Triple Bontton Line (TBL), criada por John Elkington em seu livro Canibais com Garfo e Faca, estabelece o tripé da sustentabilidade como os princípios que norteiam este conceito ao afirmar que tal feito só poderia ser atingido a partir do momento em que são observados os contextos: ambiental, econômico e social. Helleno, Moraes e Simon (2017), destacam que o desafio está em identificar os indicadores mais relevantes em cada uma das dimensões do TBL e, em compreender as conexões necessárias para alcançar verdadeiramente a sustentabilidade.

Pode-se dizer que, quando analisados isoladamente para avaliar a sustentabilidade das organizações, o propósito do contexto econômico está em observar e mensurar a viabilidade dos empreendimentos tornandoos atrativos aos investidores e a distribuição adequada e eficiente dos recursos naturais em escala adequada. A dimensão social preocupa-se com questões relacionadas aos benefícios produzidos para a sociedade, seu bem-estar e qualidade de vida, também, com o tratamento justo dos trabalhadores. Já a dimensão ambiental está centrada na observância das interações entre o processo produtivo e os danos causados ao meio ambiente e a minimização da deterioração do planeta (BELLEN, 2006); (OLIVEIRA et al., 2012).

Ainda de acordo com Oliveira et al. (2012), a união entre os pilares econômico e social resultaria em um ambiente justo. A interseção entre econômico e ambiental resultaria em viável, ao passo que, a união entre ambiental e social proporcionaria um ambiente vivível. Logo, para que haja sustentabilidade há a necessidade de interseção entre os três pilares.

\subsection{Indicadores de Sustentabilidade}

As iniciativas de desenvolver indicadores de sustentabilidade surgiram na Conferência Mundial sobre o Meio Ambiente (Rio-92) e foram relatadas na Agenda 21 sob o Título de: Informação para a Tomada de Decisões (SILVA; SOUZA-LIMA, 2010). Os esforços para a construção e elaboração de indicadores de sustentabilidade foram liderados e estimulados pela Comissão para o Desenvolvimento Sustentável (CSD), pois a existência de uma base comum possibilitaria utilizar as informações no planejamento, no processo decisório e na formulação, acompanhamento e avaliação de novas ações (BELLEN, 2004). Para Silva e Souza-Lima (2010) os indicadores são necessários para mensurar, monitorar e avaliar aspectos ambientais, econômicos, sociais, éticos e culturais a partir da definição de padrões sustentáveis de desenvolvimento. Logo, são ferramentas que possibilitam a avaliação de aspectos gerais da organização auxiliando os gestores a integrar aspectos não financeiros ao processo de tomada de decisões (RAHDARI; ROSTAMY, 2015).

De acordo com Carvalho (1995) apud Muller (2014, p.86), os indicadores de desempenho podem ser interpretados como [...] "uma forma objetiva de medir a situação real contra um padrão previamente estabelecido e consensado". Para Bellen (2005, p.42) apud Silva e SouzaLima (2010, p.56) os indicadores podem ser definidos como àqueles que são utilizados para indicar e orientar, "[...] devem ter a função de apontar para uma direção, ou mostrar em que ponto se chegou com determinadas práticas e/ou políticas". Quando os resultados obtidos não estiverem de acordo com os objetivos previamente estabelecidos, é um momento de aprendizagem organizacional em que são revisados processos e objetivos (ATKINSON, 1998).

\subsection{1 Índice de Sustentabilidade Empresarial (ISE)}

Com o intuito de estimular a responsabilidade ética no meio empresarial e criar um ambiente de investimento em demandas compatíveis com o desenvolvimento sustentável, em dezembro de 2005, foi apresentado o ISE da B3 (ZAMCOPÉ; ENSSLIN; ENSSLIN, 2012). O questionário, desenvolvido pelo Centro de Estudos em Sustentabilidade da Fundação Getúlio Vargas é uma iniciativa pioneira na América Latina e objetiva comparar o desempenho das empresas listadas na $\mathrm{B} 3$ em relação a sustentabilidade corporativa (SATOLO; SIMON; 2010); (BM\&FBOVESPA, 2016).

Além de ampliar o entendimento sobre as empresas e sobre os grupos envolvidos com a sustentabilidade, o índice 
avalia as 200 empresas com ações mais negociadas na bolsa em relação a: eficiência econômica, equilíbrio ambiental, justiça social e governança corporativa. Para garantir a transparência na construção do índice e na seleção das empresas, existe o conselho deliberativo do ISE composto por onze instituições: B3, APIMEC, ANBIMA, ABRAPP, ETHOS, IBGC, IBRACON, IFC, GIFE, MMA e ONU Meio Ambiente (BM\&FBOVESPA, 2016).

O ISE é uma ferramenta para análise comparativa da performance das empresas listadas na B3 sob o aspecto da sustentabilidade corporativa, baseada em eficiência econômica, equilíbrio ambiental, justiça social e governança corporativa. Também, amplia o entendimento sobre empresas e grupos comprometidos com a sustentabilidade, diferenciando-os em termos de qualidade, nível de compromisso com o desenvolvimento sustentável, equidade, transparência e prestação de contas, natureza do produto, além do desempenho empresarial nas dimensões econômico-financeira, social, ambiental e de mudanças climáticas (BM\&FBOVESPA, 2016)

Os questionários que compõem o ISE subdividemse em sete dimensões, às três que compõem o TBL, ambiental, econômica e social, foram agregadas outras quatro: geral, governança corporativa, mudança do clima e natureza do produto. Cada uma das dimensões descritas, é novamente subdividida em critérios de análise. De acordo com o estudo de Satolo e Simon (2010), o ISE realiza a triangulação entre as fontes de informação tornando a avaliação mais fidedigna, porém, é um questionário extenso e de preenchimento complexo, além de não disponibilizar o resultado para os respondentes.

\subsubsection{Indicadores Ethos de Responsabilidade Social Empresarial - RSE}

Com o objetivo construir uma sociedade justa e sustentável, o Instituto Ethos - Empresas e Responsabilidade Social, organização sem fins lucrativos, tem o intuito de mobilizar as empresas e sensibilizá-las com relação à gestão socialmente responsável dos empreendimentos servindo como uma ferramenta que possibilita, a partir do preenchimento dos questionários, que a organização realize uma auto avaliação e identifique o que necessita ser ajustado, passando assim por um processo de aprendizagem (SATOLO; SIMON, 2010).

Os Indicadores Ethos têm o intuito de ser a ferramenta necessária para fornecer um autodiagnóstico que apoia as empresas na implantação da responsabilidade social empresarial e da sustentabilidade. O questionário, preenchido online, passa por reavaliação e aprimoramento contínuo. Está alinhado e mantém integração com as diretrizes e relatórios de sustentabilidade do Global Reporting Initiative, com a Norma de Responsabilidade Ambiental Social ABNT NBR ISO 26000, e outras iniciativas (INSTITUTO ETHOS DE EMPRESAS E RESPONSABILIDADE SOCIAL, 2016).

De acordo com Zamcopé, Ensslin e Ensslin (2012), os Indicadores Ethos de Responsabilidade Empresarial, além de aferir o grau de sustentabilidade do empreendimento, auxiliam a organização a planejar os próximos passos em direção à sustentabilidade corporativa. Servem como instrumento norteador do posicionamento estratégico promovendo a harmonia entre a geração de resultados financeiros, sociedade e meio ambiente.

Conforme o Instituto Ethos de Empresas e Responsabilidade Social (2017), o questionário é flexível e alinhado a maturidade na gestão de cada empreendimento. Assim, as organizações são orientadas a escolher os indicadores que façam mais sentido a sua realidade. Deste modo, as empresas vão ampliando o seu grau de maturidade em relação à RSE/Sustentabilidade e passam a contemplar mais indicadores em sua gestão. Para construir o autodiagnóstico das empresas participantes, inicialmente os indicadores são subdivididos em quatro dimensões: Visão e Estratégia, Governança e Gestão, Social e Ambiental. Após, é realizada uma subdivisão em Temas e Subtemas. Exceto pela Dimensão Visão Estratégica, que contempla indicadores como: Estratégias para a Sustentabilidade, Proposta de Valor e Modelo de Negócios.

\subsubsection{Guia de Sustentabilidade Revista Exame}

Nos anos de 2016 e 2017, o Guia de Sustentabilidade da Revista Exame chegou a sua $17^{\mathrm{a}}$ e $18^{\mathrm{a}}$ edição respectivamente. Ele contempla, a cada ano, a lista das empresas, mais sustentáveis do país. Na edição de 2016 utilizada neste estudo,190 empresas responderam ao questionário online composto de 140 questões divididas em quatro dimensões distintas: geral, ambiental, econômica e social.

A dimensão geral, subdividida em cinco critérios e composta por doze indicadores avalia se existem processos implementados para gerenciar situações que envolvam corrupção, publicação de relatórios com informações econômicas, sociais e ambientais de maneira integrada. Também, se o conselho de administração contempla questões socioambientais à estratégia e à operação (REVISTA EXAME 2016). 
Por sua vez, a dimensão econômica traz questões relativas ao gerenciamento dos riscos corporativos econômicos, sociais e ambientais de forma integrada. Composta por três critérios e nove indicadores, busca avaliar ativos intangíveis e os processos implementados para gerenciá-los bem como, gerencia oportunidades que resultem em ganhos para companhia, ao meio ambiente e para a sociedade (REVISTA EXAME, 2016).

Na dimensão social, os cinco critérios e os dezenove indicadores buscam avaliar as relações de trabalho, com fornecedores, clientes e sociedade. Já na dimensão ambiental, riscos e oportunidades que os serviços prestados pela natureza representam para a operação. Os cinco critérios e dezessete indicadores contemplam: impactos ambientais diretos e indiretos, etapa de pós consumo, desenvolvimento de pesquisa e inovação para o uso eficiente de recursos e produção mais limpa (REVISTA EXAME, 2016).

Finda a apresentação dos itens contemplados na revisão bibliográfica, passa-se a apresentação da metodologia utilizada na pesquisa.

\section{MÉTODO}

O presente estudo teve uma etapa exploratória na qual buscou aprofundar os conhecimentos em relação ao objeto de análise, principalmente com relação aos indicadores de sustentabilidade empresarial. Também, teve uma etapa descritiva, momento em que se fez a descrição dos modelos de avaliação da sustentabilidade empresarial analisando a sua estrutura e composição. Em ambas, as fontes de pesquisa utilizadas foram bibliográficas.

A pesquisa foi qualitativa no momento da análise da estrutura e da frequência de repetição dos indicadores utilizados e quantitativa no momento da análise estatística dos questionários. Teve como unidade de análise, micro e pequenas empresas do segmento agroindustrial participantes do Arranjo Produtivo Local - APLAgroindústrias Familiares do Vale do Taquari/RS, Brasil. Os Arranjos Produtivos Locais (APLs) podem ser definidos como aglomerações de empresas e empreendimentos de uma mesma localidade ou território com a mesma especialização produtiva (BRASIL, 2018).

Também, fizeram parte da população acadêmicos das áreas de gestão e sustentabilidade da Universidade do Vale do Taquari - UNIVATES. Obteve-se a resposta de 35 pessoas, 10 proprietários de agroindústrias e 25 acadêmicos. Faz-se necessário lembrar que as agroindústrias associadas ao APL se enquadram como micro e pequenas empresas conforme critérios de avaliação do porte empresarial utilizados pelo SEBRAE.
Com o objetivo de mesurar a importância dos indicadores selecionados com base na frequência de repetição, elaborou-se um questionário atribuindo a cada um deles uma escala de 1 à 7 , na qual 1 representa ser pouco importante e 7 muito importante na mensuração da sustentabilidade empresarial. A mesma escala foi utilizada para medir a dificuldade em relação a obtenção das informações para elaboração dos indicadores, porém, nesta oportunidade 1 representa ser de fácil obtenção e 7 de difícil obtenção.

A principal ferramenta utilizada nesta pesquisa foi a planilha eletrônica. Tanto na etapa inicial, em que se fez o detalhamento e comparação da estrutura e composição dos modelos de avaliação da sustentabilidade, como no momento de tabular os dados dos questionários. Também, foram utilizadas para elaborar os gráficos e cálculos de média e desvio padrão. Faz-se necessário observar que para cálculo das médias, utilizou-se a soma das multiplicações entre a frequência de repetição e o peso atribuído na escala de 1 a 7 dividido pelo somatório das frequências de repetição.

Para avaliação final quanto ao cruzamento entre as informações da importância atribuída ao indicador na mensuração da sustentabilidade empresarial com relação a dificuldade de obtenção das informações para elaboração dos respectivos indicadores, desenvolveu-se uma matriz observando a lógica utilizada por Slack (Figura 1) em sua Matriz de Importância x Desempenho.

De acordo com Slack (2018), com a utilização da matriz pode-se avaliar cada um dos fatores a partir da comparação de sua importância e desempenho. A disposição dos fatores de acordo com suas pontuações irá alocá-los em zonas de prioridade. Com o objetivo de aplicar a mesma lógica descrita na Matriz de Importância x Desempenho, fez-se algumas adequações que tornaram possível utilizá-la para cruzar as informações dos indicadores de sustentabilidade quanto a sua importância e dificuldade de obtenção/elaboração.

Deste modo, para proceder com as modificações necessárias na matriz, o primeiro passo foi definir em quais dos eixos seriam alocadas as variáveis importância e grau de dificuldade. Entendeu-se mais coerente ao objetivo a que se propôs esta pesquisa, considerar no eixo " $\mathrm{x}$ " a escala referente ao grau de importância utilizada no questionário. Em contrapartida, a escala referente a classificação do grau de dificuldade na obtenção dos indicadores foi alocada no eixo "y”. Realizadas as adequações, fez-se o cruzamento das informações das médias de cada indicador em um gráfico de dispersão utilizando-se a matriz contemplada na Figura 2 como referência. 


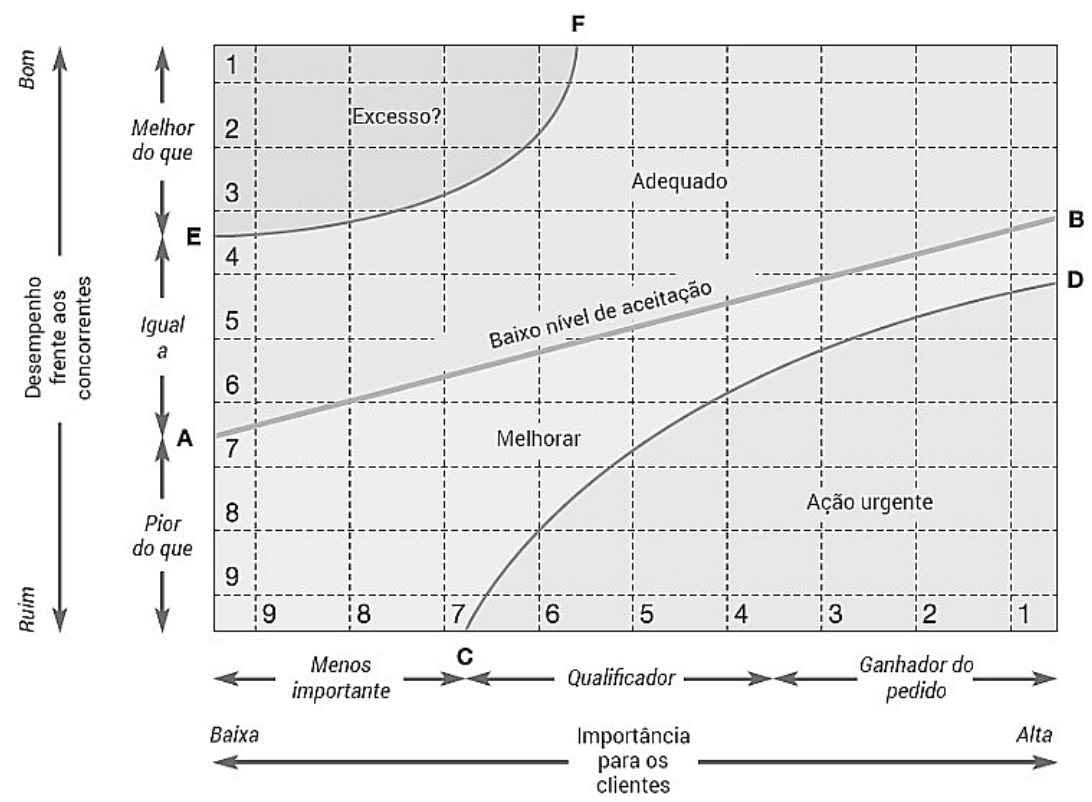

FIGURA 1 - Matriz de Importância x Desempenho

Fonte: Slack (2018, p.103)

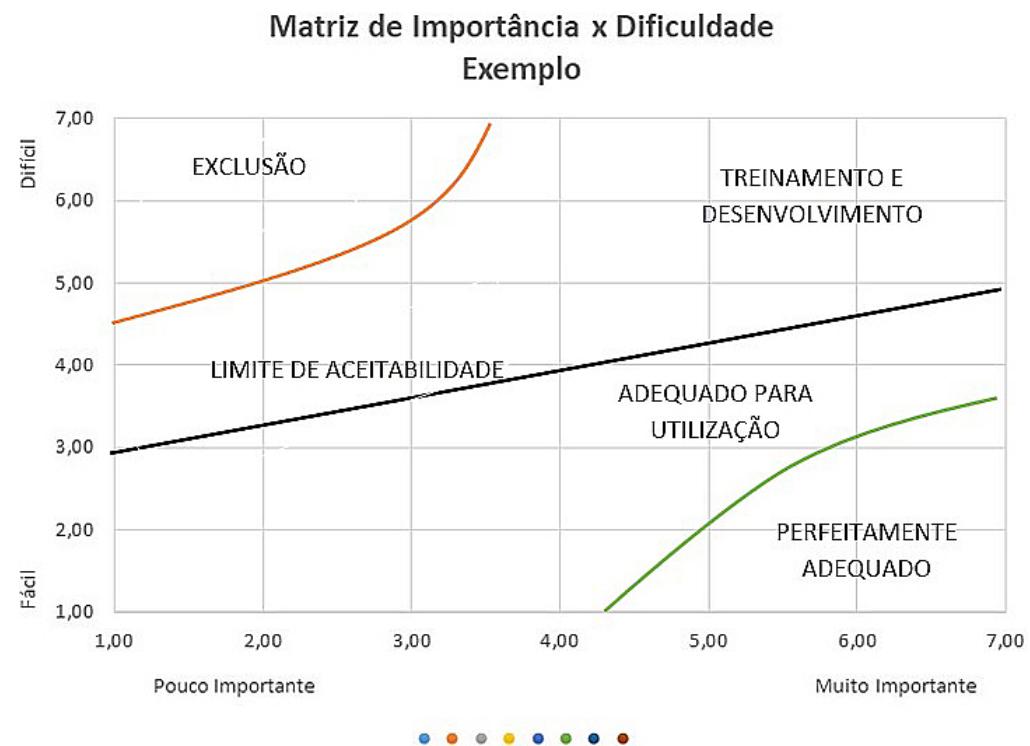

FIGURA 2 - Matriz de Importância x Dificuldade

Fonte: Dos Autores (2019)

Para definir qual seria o limite de aceitabilidade dos indicadores traçou-se uma linha diagonal na matriz. Com o objetivo de estabelecer os pontos inicial e final, da linha a ser considerada como limite, utilizou-se os pontos médios da tabela. Logo, admitiu-se que indicadores pouco importantes (1) poderiam ter no máximo grau de dificuldade 3, e indicadores muito importantes (7), poderiam ter no máximo grau de dificuldade igual a 5 . Logo a reta linear utilizada, tem início na interseção dos pontos $(1,3)$ e final na interseção dos pontos $(7,5)$.

Organizações Rurais \& Agroindustriais, Lavras, v. 21, n. 1-3, p. 79-93, 2019 
O quadrante de excesso, no qual sugere-se que os indicares sejam excluídos contemplará aqueles em que a importância atribuída for menor que 3,5 e grau de dificuldade superior a 4,5. No quadrante de perfeitamente adequado para a utilização ficarão os indicadores que receberem importância superior à 4,5 e obtiverem avaliação quanto ao seu grau de dificuldade inferior a 3,5. Os indicadores que permanecerem acima do limite de aceitabilidade deverão ser questionados quanto à sua aplicabilidade. E em caso de necessidade de utilização, deverão ser precedidos de treinamento e desenvolvimento. Aqueles que não excederem ao limite de aceitabilidade serão considerados aptos para utilização.

A pesquisa teve como foco específico micro e pequenas empresas do segmento agroindustrial. Portanto, o conjunto de indicadores e a sistemática de avaliação do grau de sustentabilidade serão específicos para a realidade deste segmento. Também, se faz necessário observar, que não foi obtido um número de respostas equivalentes por grupo. Foram coletadas as respostas de 10 empresários e de 25 pesquisadores e acadêmicos. Logo, para efeitos de avaliação a partir da média do conjunto de respostas, a participação dos empresários representa pouco menos de $30 \%$ em relação ao total. Assim, a avaliação realizada pelos acadêmicos acabou por ter um peso maior na classificação geral dos indicadores quanto à sua importância e grau de dificuldade na elaboração/obtenção das informações.

\section{APRESENTAÇÃO DOS RESULTADOS}

Para viabilizar a escolha dos indicadores iniciou-se a pesquisa avaliando a estrutura dos modelos utilizados. As dimensões ambiental e social foram contempladas nos três modelos descritos. Quanto a avalição na dimensão econômica, o Instituto Ethos apenas utiliza outra nomenclatura, contemplando questões relacionadas aos resultados econômicos do empreendimento juntamente com a dimensão governança e gestão. Logo, pode-se afirmar que ambos contemplam em seus indicadores o TBL.

Além do TBL, as práticas de governança corporativa, embora organizadas de forma distinta nos questionários, também são observadas por ambos. O ISE trata este tema em uma dimensão específica, enquanto que no conjunto de indicadores utilizado pelo Instituto Ethos as temáticas gestão e governança compõem a mesma dimensão de análise. Cabe ressaltar, que o ISE se diferencia dos demais por dar mais evidência as mudanças climáticas e a natureza dos produtos, atribuindo-lhes uma dimensão específica de análise.

Para subsidiar a elaboração do questionário e servir como estrutura inicial do conjunto de indicadores de sustentabilidade a que se propôs este estudo, tendo como base a análise das dimensões descrita acima, fez-se a proposição de utilização das seguintes dimensões de avaliação: Gestão e Governança Corporativa, EconômicoFinanceira, Social e Ambiental.

Justifica-se a escolha das dimensões, afirmando a importância de utilizar o TBL como referência na escolha dos indicadores de sustentabilidade. Esta afirmação encontra subsídios na obra de Oliveira et al. (2012), quando afirmar que a sustentabilidade é o resultado da interseção entre os três pilares do TBL. Também, entendeu-se necessário e coerente avaliar os aspectos relacionados à Gestão e Governança dentro de uma mesma dimensão, em razão de serem complementares. Justifica-se a opção, observando o que conceitua Silveira (2015), quando se refere a governança corporativa como os mecanismos utilizados para conduzir e controlar as sociedades, citando como principais atores do processo a diretoria os conselhos de administração e os acionistas. Esta sistemática de avaliação já é utilizada pelo Instituto Ethos de RSE em seu conjunto de indicadores.

Os indicares escolhidos de acordo com sua frequência de repetição foram agrupados em temas e alocados em suas respectivas dimensões. Para demonstrar a média e os desvio padrão da importância atribuída a cada um dos indicadores na mensuração da sustentabilidade empresarial e o grau de dificuldade para obtenção das informações, foram elaboradas tabelas por dimensão nas quais serão demonstrados o conjunto de indicadores e sua respectiva avaliação quanto a importância e dificuldade na elaboração dos indicadores.

\subsection{Dimensão Gestão e Governança}

Ao realizar a análise das informações descritas Tabela 1, percebe-se que todos os indicadores da dimensão gestão e governança foram julgados como importantes e, a classificação do grau de dificuldade está próxima ao ponto médio da escala. Pode-se avaliar que o desvio padrão das respostas quanto ao grau de dificuldade é superior ao encontrado para as avaliações quanto ao grau de importância do indicador, demonstrando que há maior discordância dos respondentes na avaliação quanto a obtenção das informações necessárias à elaboração dos indicadores. Destaca-se ainda, que as respostas foram mais dispersas nos indicadores referentes ao cumprimento da legislação e regulamentos impostos a atividade e o indicador de elaboração e utilização do código de conduta.

$\mathrm{Na}$ Matriz (Figura 3) que expõe o cruzamento entre as médias de cada indicador quanto a sua importância e dificuldade, pode-se perceber, que todos os indicadores desta dimensão podem ser considerados adequados para utilização na avaliação da sustentabilidade empresarial. 
TABELA 1 - Dimensão Gestão e Governança

\begin{tabular}{|c|c|c|c|c|c|}
\hline \multirow{2}{*}{\multicolumn{2}{|c|}{ TEMAS E INDICADORES }} & \multicolumn{2}{|c|}{ IMPORTÂNCIA } & \multicolumn{2}{|c|}{ DIFICULDADE } \\
\hline & & Média & Desv. Pad. & Média & Desv. Pad. \\
\hline \multicolumn{6}{|c|}{ 1.1 Planejamento Estratégico } \\
\hline 1.1 .1 & Elaboração do Planejamento Estratégico; & 6,09 & 1,05 & 4,40 & 1,27 \\
\hline 1.1 .2 & $\begin{array}{l}\text { Contemplar no planejamento estratégico ações voltadas a } \\
\text { Responsabilidade Social e Empresarial; }\end{array}$ & 5,86 & 1,15 & 4,46 & 1,25 \\
\hline 1.1 .3 & $\begin{array}{l}\text { Conhecer os elos mais importantes, bem como, o } \\
\text { posicionamento do empreendimento na cadeia de valor; }\end{array}$ & 5,83 & 1,18 & 4,57 & 1,42 \\
\hline \multicolumn{6}{|c|}{ 1.2 Modelo de Negócios e Código de Conduta } \\
\hline 1.2 .1 & Elaboração/utilização de código de conduta; & 5,83 & 1,13 & 4,34 & 1,84 \\
\hline 1.2 .2 & $\begin{array}{l}\text { Cumprimento da legislação e regulamentos impostos à } \\
\text { atividade; }\end{array}$ & 6,23 & 0,99 & 4,17 & 1,98 \\
\hline 1.2 .3 & $\begin{array}{l}\text { Compromisso formal com relação ao combate de todas as } \\
\text { formas de corrupção; }\end{array}$ & 5,89 & 1,24 & 4,17 & 1,54 \\
\hline \multicolumn{6}{|c|}{1.3 Observância dos Princípios de Governança Corporativa } \\
\hline 1.3 .1 & Transparência e integridade das informações; & 5,89 & 1,12 & 3,97 & 1,25 \\
\hline 1.3 .2 & $\begin{array}{l}\text { Prestação de contas e tratamento justos aos Stakeholders* } \\
\text { da Organização; }\end{array}$ & 6,06 & 0,92 & 4,29 & 1,52 \\
\hline
\end{tabular}

Fonte: Dos Autores (2019)

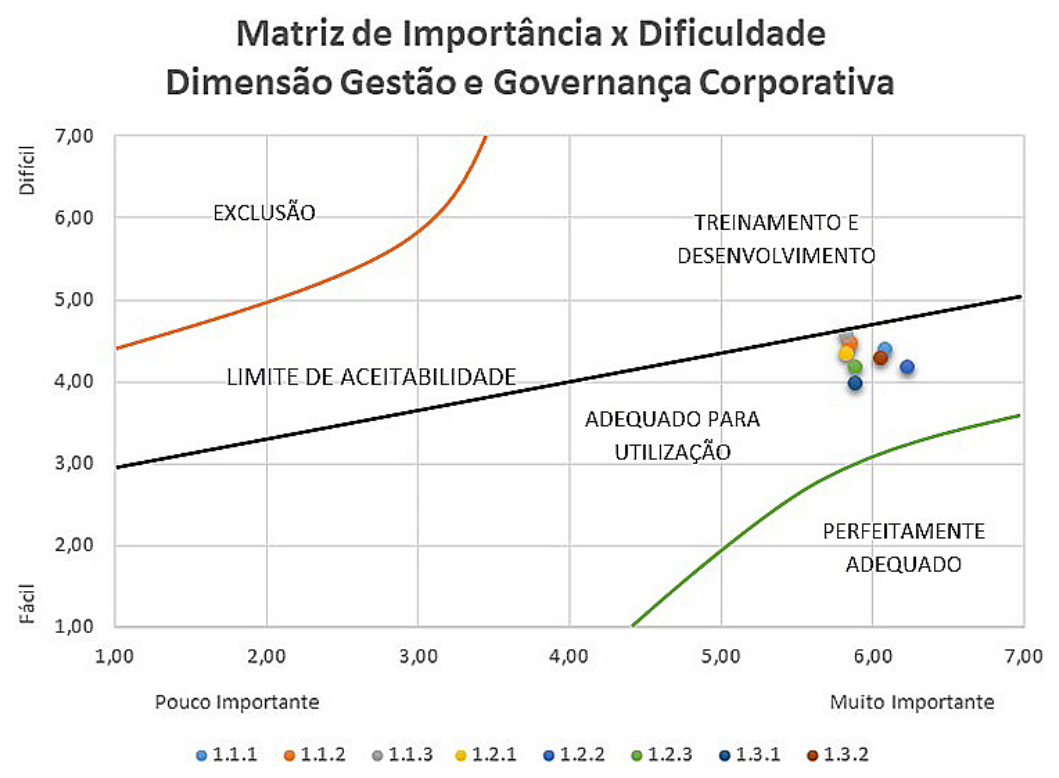

FIGURA 3 - Matriz de Importância x Dificuldade: Dimensão Gestão e Governança Corporativa Fonte: Dos autores (2019)

Ficaram mais próximos ao limite máximo de adequados para utilização os indicadores: contemplar no planejamento estratégico ações voltadas a responsabilidade social empresarial e; conhecer os elos mais importantes, bem como, o posicionamento do empreendimento na cadeia de valor. Em tempo, para viabilizar a visualização da figura, na legenda utilizou-se o número atribuído a cada indicador conforme descrito na Tabela 1.

Organizações Rurais \& Agroindustriais, Lavras, v. 21, n. 1-3, p. 79-93, 2019 


\subsection{Dimensão Econômico-Financeira}

Com relação aos indicadores propostos para a dimensão econômico-financeira descritos na Tabela 2, pode-se dizer, de forma geral, que todos foram considerados importantes e de médio grau de dificuldade.

Novamente o grau de dificuldade atribuído aos indicadores apresenta maior desvio padrão quando comparado ao grau de importância. Em relação a importância, os indicadores de avalição contínua de riscos e oportunidades e o plano de contingência para evitar momentos de dificuldade obtiverem importância significativa.

Pode-se observar, a partir da Figura 4, que os indicadores referentes a avaliação dos ativos intangíveis, avaliação contínua dos riscos e oportunidades e plano de contingência para evitar momentos de dificuldade ficaram junto ao limite de aceitabilidade dos indicadores adequados para utilização.

Embora tenham sido considerados importantes na avaliação, o estudo mostra que poderia ser significativo treinar e desenvolver os profissionais para que possam utilizar os indicadores sugeridos de maneira eficaz.

Quanto a avaliação periódica das demonstrações contábeis, pode-se afirmar, até o presente momento, que é um dos indicadores em que a relação estabelecida entre a importância e dificuldade de obtenção o aproxima do quadrante determinado como perfeitamente adequado para utilização na avalição da sustentabilidade.

TABELA 2 - Dimensão Econômico-Financeira

\begin{tabular}{|c|c|c|c|c|}
\hline \multirow{2}{*}{ TEMAS E INDICADORES } & \multicolumn{2}{|c|}{ IMPORTÂNCIA } & \multicolumn{2}{|c|}{ DIFICULDADE } \\
\hline & Média & Desv. Pad. & Média & Desv. Pad. \\
\hline \multicolumn{5}{|l|}{ 2.1 Ativos Intangíveis. } \\
\hline 2.1.1 Avaliação dos Ativos Intangíveis*. & 5,46 & 1,18 & 4,46 & 1,54 \\
\hline \multicolumn{5}{|l|}{ 2.2 Gerenciamento de Riscos e Oportunidades. } \\
\hline 2.2.1 Avaliação contínua dos riscos e oportunidades. & 6,11 & 1,17 & 4,66 & 1,47 \\
\hline $\begin{array}{l}\text { 2.2.2 Plano de contingência para evitar momentos de } \\
\text { dificuldade. }\end{array}$ & 6,03 & 1,08 & 4,66 & 1,58 \\
\hline \multicolumn{5}{|l|}{ 2.3 Relatórios Financeiros. } \\
\hline 2.3.1 Avaliação periódica das demonstrações financeiras. & 6,29 & 0,96 & 3,46 & 1,73 \\
\hline
\end{tabular}

Fonte: Dos autores (2019)

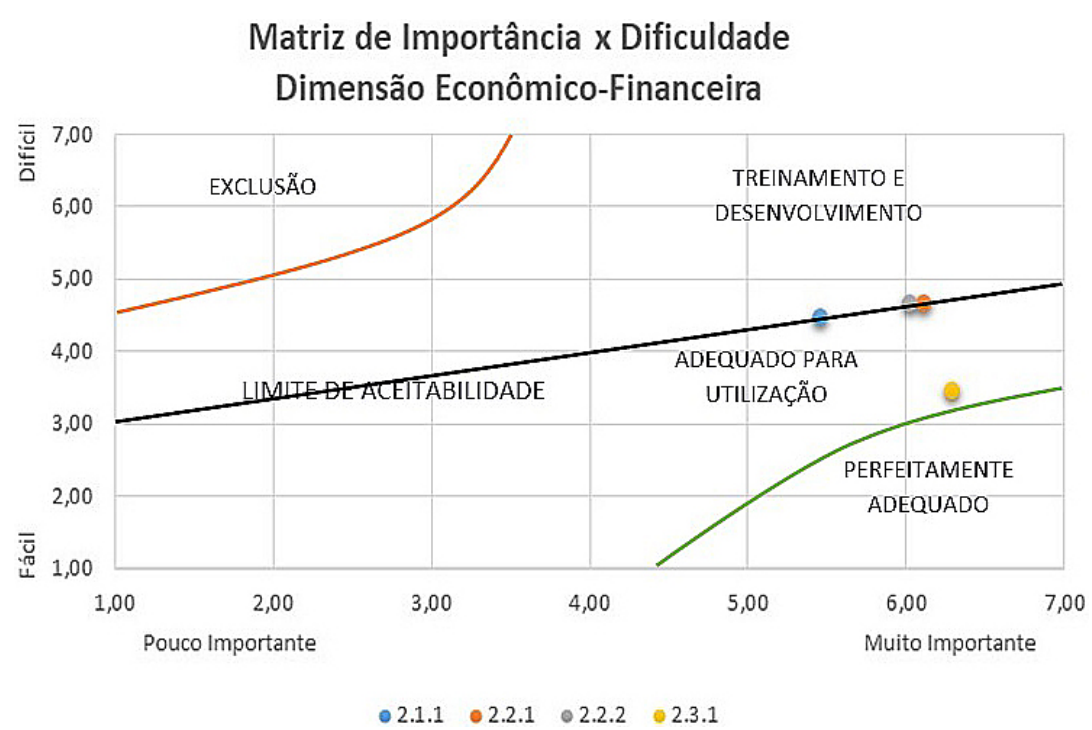

FIGURA 4 - Matriz de Importância x Dificuldade: Dimensão Econômico-Financeira Fonte: Dos autores (2019) 


\subsection{Dimensão Social}

Por sua vez, a Dimensão Social é aquela que possui o maior número de indicadores para avaliação, assim, para viabilizar a elaboração das tabelas e figuras, os indicadores foram subdivididos em dois grupos denominados de Parte 01 e Parte 02. Dentre os indicadores descritos na Tabela 3, pode-se destacar a importância atribuída aos indicadores: cumprimento da legislação trabalhista, não discriminação e valorização da diversidade e inexistência de trabalho infantil, forçado ou compulsório, que receberam maior classificação quanto a sua importância.

Também, sua média em relação ao grau de dificuldade ficou abaixo do ponto médio da escala. Porém, há necessidade de ressaltar que são os indicadores em que desvio padrão quanto a classificação da dificuldade foi o mais elevado, o que demonstra relativa divergência entre a opinião dos respondentes.

Na Figura 5, pode-se perceber que os indicadores inexistência de trabalho infantil, forçado ou compulsório (3.2.1) e cumprimento da legislação trabalhista (3.2 4), são os que ficaram mais próximos à classificação de perfeitamente adequado para utilização.

Ao passo que, o indicador de avaliação dos impactos da atividade na sociedade (3.1.1) foi o que se apresentou próximo ao limite máximo de enquadramento para utilização sem necessidade de acompanhamento ou ajustes quanto a proposição.

TABELA 3 - Dimensão Social: Parte 01

\begin{tabular}{|c|c|c|c|c|c|}
\hline \multirow{2}{*}{\multicolumn{2}{|c|}{ TEMAS E INDICADORES }} & \multicolumn{2}{|c|}{ IMPORTÂNCIA } & \multicolumn{2}{|c|}{ DIFICULDADE } \\
\hline & & Média & Desv. Pad. & Média & Desv. Pad. \\
\hline \multicolumn{6}{|c|}{ 3.1 Compromisso com o desenvolvimento da comunidade e gestão de ações sociais. } \\
\hline 3.1 .1 & Avaliação dos impactos da atividade na sociedade. & 6,00 & 1,15 & 4,57 & 1,42 \\
\hline 3.1 .2 & Apoiar ações sociais e de desenvolvimento da comunidade. & 5,49 & 1,36 & 4,11 & 1,54 \\
\hline 3.1 .3 & Incentivar e desenvolver ações que promovam a cultura local. & 5,40 & 1,25 & 4,03 & 1,40 \\
\hline \multicolumn{6}{|c|}{ 3.2 Compromisso com os princípios e direitos fundamentais nas relações de trabalho. } \\
\hline 3.2 .1 & Inexistência de trabalho infantil, forçado ou compulsório. & 6,31 & 1,01 & 3,34 & 2,08 \\
\hline 3.2 .2 & Inexistência de assédio moral e sexual. & 6,09 & 1,38 & 4,17 & 1,87 \\
\hline 3.2 .3 & Não discriminação e valorização da diversidade. & 6,34 & 0,92 & 3,88 & 2,03 \\
\hline 3.2 .4 & Cumprimento da legislação trabalhista. & 6,51 & 0,94 & 3,54 & 1,98 \\
\hline
\end{tabular}

Fonte: Dos autores (2019)

\section{Matriz de Importância x Dificuldade Social - Parte 01}

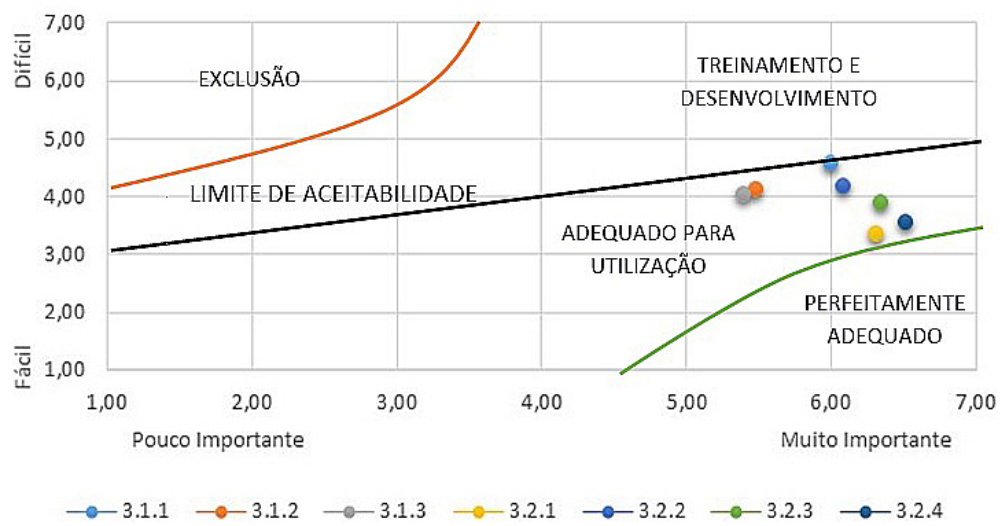

FIGURA 5 - Matriz de Importância x Dificuldade - Dimensão Social: Parte 01

Fonte: Dos autores (2019)

Organizações Rurais \& Agroindustriais, Lavras, v. 21, n. 1-3, p. 79-93, 2019 
Os indicadores de sustentabilidade empresarial contemplados nos temas condições de trabalho, qualidade de vida, desenvolvimento profissional e remuneração adequada e; relacionamento com clientes fornecedores e consumidores, estão contemplados na segunda etapa de avaliação da dimensão social denominada para este estudo de parte 2 . Conforme destacado na Tabela 4, pode-se evidenciar que para este grupo de indicadores, as avaliações quanto a importância, ficaram abaixo de 6 somente para os indicadores relacionados a priorização da compra de fornecedores locais e o fato de possuir canal de comunicação aberto com clientes (ouvidoria). Em tempo, salienta-se que mesmo ficando abaixo da média atribuída aos demais indicadores são avaliações importantes a serem consideradas para medir a sustentabilidade.

Ao fazer a transposição das informações da Tabela 4 para a Figura 6, pode-se verificar que, certamente em função de um grau de dificuldade menor na obtenção das informações o conjunto de indicadores permaneceu dentro do limite de adequado para a utilização. Alguns, como é o caso dos indicadores identificados sob os números 3.3.3, 3.4.1, 3.4.4 e 3.4.5, ficaram próximo ao limite de enquadramento como indicadores perfeitamente adequados para a utilização.

Destes indicadores mencionados anteriormente, o primeiro faz referência ao pagamento de remuneração justa e adequada ao mercado de trabalho. Refere-se, portanto, à relação de trabalho. Os demais, são todos elencados ao tema que contempla indicadores referentes ao relacionamento com clientes e fornecedores. Remetem a importância de conhecer manter o bom relacionamento ético e transparente com clientes e fornecedores, e também quanto ao sigilo das informações de seus clientes.

Pode-se apontar ainda, a classificação do indicador referente priorização de relações com fornecedores que cumpram as legislações e regulamentos trabalhistas, tributários, sanitários e ambientais, que nesta matriz ficou um pouco deslocado dos demais indicadores do grupo analisado. Esta classificação sinaliza, e reforça o que de certa forma é possível visualizar ao analisar a Figura 6, os respondentes compreendem a importância do indicador, porém ao mesmo tempo visualizam dificuldades no decorrer do processo.

Fazendo uma análise geral da dimensão social considerando todo o conjunto de indicadores, pode-se afirmar que os que foram contemplados no tema compromisso com o desenvolvimento da comunidade e gestão de ações sociais obtiveram uma classificação maior com relação ao seu grau de dificuldade. Além do indicador referente a inexistência de assédio moral e sexual nas relações de trabalho, o que versa sobre priorizar relações com fornecedores que cumpram as legislações e regulamentos trabalhistas, tributários, sanitários e ambientais também apresentou grau de dificuldade e desvio padrão elevado.

TABELA 4 - Dimensão Social: parte 2

\section{TEMAS E INDICADORES}

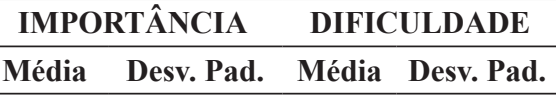

3.3 Condições de trabalho, qualidade de vida, desenvolvimento profissional e remuneração adequada

\begin{tabular}{|c|c|c|c|c|c|}
\hline 3.3 .1 & $\begin{array}{l}\text { Realização de ações voltadas ao desenvolvimento pessoal e profissional } \\
\text { dos colaboradores. }\end{array}$ & 6,03 & 1,16 & 3,74 & 1,78 \\
\hline 3.3 .2 & $\begin{array}{l}\text { Realizar ações que propiciem maior qualidade de vida aos } \\
\text { colaboradores. }\end{array}$ & 6,06 & 0,92 & 3,74 & 1,76 \\
\hline 3.3 .3 & Remuneração justa e adequada ao mercado de trabalho. & 6,37 & 0,93 & 3,57 & 1,92 \\
\hline \multicolumn{6}{|c|}{ 3.4 Relacionamento com clientes fornecedores e consumidores } \\
\hline 3.4 .1 & Ter conhecimento de quem são seus principais fornecedores. & 6,26 & 1,00 & 3,54 & 1,86 \\
\hline 3.4 .2 & Priorizar a compra de fornecedores locais. & 5,57 & 1,23 & 3,37 & 1,82 \\
\hline 3.4 .3 & $\begin{array}{l}\text { Priorizar relações com fornecedores que cumpram as legislações e } \\
\text { regulamentos trabalhistas, tributários, sanitários e ambientais. }\end{array}$ & 6,40 & 0,93 & 4,29 & 1,95 \\
\hline 3.4 .4 & $\begin{array}{l}\text { Manter relações éticas e transparentes com os clientes respeitando } \\
\text { prazos previamente estabelecidos. }\end{array}$ & 6,31 & 1,04 & 3,34 & 1,58 \\
\hline 3.4 .5 & Assegurar sigilo às informações cadastrais dos clientes. & 6,14 & 1,12 & 3,43 & 1,99 \\
\hline 3.4 .6 & Possuir canal de comunicação aberto com os clientes (ouvidoria). & 5,71 & 1,32 & 3,29 & 1,72 \\
\hline
\end{tabular}

Fonte: Dos autores (2019) 


\subsubsection{Dimensão Ambiental}

Na avaliação dos indicadores que compõem a dimensão ambiental, pode-se verificar a preocupação dos respondentes quanto ao consumo sustentável de recursos. Cita-se como exemplo o grau de importância atribuído (Tabela 5) aos indicadores de: controle do consumo de água, controle do consumo de energia; controle do consumo de recursos naturais e controle do consumo de materiais em geral. Em tempo, faz-se necessário destacar que há relativa divergência entre as avaliações relativas ao grau de dificuldade na obtenção das informações para elaboração dos respectivos indicadores, dado o elevado desvio padrão das respostas.

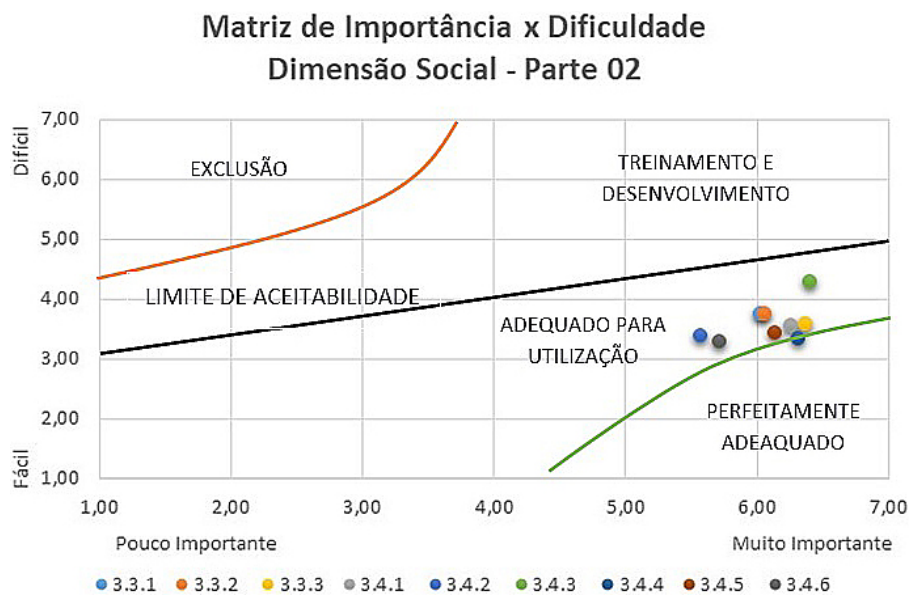

FIGURA 6 - Matriz de Importância x Dificuldade - Dimensão Social: Parte 2

Fonte: Dos autores (2019)

TABELA 5 - Dimensão Ambiental

\begin{tabular}{|c|c|c|c|c|c|}
\hline \multirow{2}{*}{\multicolumn{2}{|c|}{ TEMAS E INDICADORES }} & \multicolumn{2}{|c|}{ IMPORTÂNCIA } & \multicolumn{2}{|c|}{ DIFICULDADE } \\
\hline & & Média & Desv. Pad. & Média & Desv. Pad. \\
\hline \multicolumn{6}{|c|}{ 4.1 Consumo Sustentável de Recursos } \\
\hline 4.1.1 & Controle do consumo de água. & 6,37 & 1,02 & 3,06 & 1,94 \\
\hline 4.1 .2 & Controle do consumo de energia. & 6,29 & 1,20 & 3,14 & 1,88 \\
\hline 4.1.3 & Controle do consumo de recursos naturais. & 6,29 & 1,03 & 3,74 & 1,59 \\
\hline 4.1.4 & Controle do consumo de materiais em geral. & 6,29 & 0,91 & 3,46 & 1,71 \\
\hline \multicolumn{6}{|c|}{ 4.2 Controle da emissão de resíduos e ações de logística reversa. } \\
\hline 4.2.1 & Elaboração de políticas de logística reversa. & 6,03 & 1,00 & 4,26 & 1,44 \\
\hline 4.2.2 & Controle de emissões atmosféricas, efluentes líquidos e resíduos. & 6,34 & 0,98 & 4,46 & 1,63 \\
\hline \multicolumn{6}{|c|}{4.3 Gestão de ações relacionadas às mudanças climáticas } \\
\hline 4.3 .1 & $\begin{array}{l}\text { Realizar estudos relacionados à mudanças climáticas e possíveis } \\
\text { adaptações ao processo produtivo. }\end{array}$ & 5,66 & 1,47 & 5,26 & 1,44 \\
\hline \multicolumn{6}{|c|}{$\begin{array}{l}\text { 4.4 Respeito às áreas de preservação permanente, reservas legais e controle de } \\
\text { passivos ambientais }\end{array}$} \\
\hline 4.4 .1 & $\begin{array}{l}\text { Comprovar o cumprimento da legislação referente às áreas de } \\
\text { preservação permanente e reservas legais. }\end{array}$ & 6,29 & 0,94 & 3,77 & 1,66 \\
\hline \multicolumn{6}{|c|}{ 4.5 Responsabilidade e Gestão Ambiental } \\
\hline 4.5.1 & Iniciativas de monitoramento de riscos e passivos ambientais. & 6,20 & 1,06 & 4,37 & 1,66 \\
\hline 4.5.2 & Dispor de sistemas de gestão ambiental. & 5,89 & 1,21 & 4,23 & 1,51 \\
\hline
\end{tabular}

Fonte: Dos autores (2019)

Organizações Rurais \& Agroindustriais, Lavras, v. 21, n. 1-3, p. 79-93, 2019 
Ainda de acordo com a Tabela 5, pode-se verificar que os indicadores relativos ao controle de emissões atmosféricas, efluentes líquidos e resíduos (4.2.2) também obtiveram classificação elevada quanto a importância, bem como referente à dificuldade na obtenção das informações. $\mathrm{Na}$ Tabela 5, pode-se evidenciar as médias atribuídas aos indicadores da dimensão ambiental e o seu respectivo desvio padrão.

Pode-se perceber, em função do grau de dificuldade atribuído pelos respondentes, que o indicador referente aos estudos relacionados a mudanças climáticas e possíveis adaptações ao processo produtivo necessita de acompanhamento, treinamento e desenvolvimento para que possa ser implementado no conjunto dos indicadores utilizados para avaliação das micro e pequenas empresas.

Conforme Figura 7, trata-se do único indicador a ser retirado do conjunto neste primeiro momento, sugerindo que, para obter resultados eficazes a partir de sua avaliação as empresas objeto deste estudo não contam com infraestrutura e conhecimento necessários para conduzir estudos relacionados a mudanças climáticas e possíveis adaptações ao processo produtivo.

Finalizada a apresentação dos resultados da pesquisa, no capítulo a seguir, serão apresentadas as conclusões e considerações finais.

\section{Matriz de Importância x Dificuldade Dimensão Ambiental}

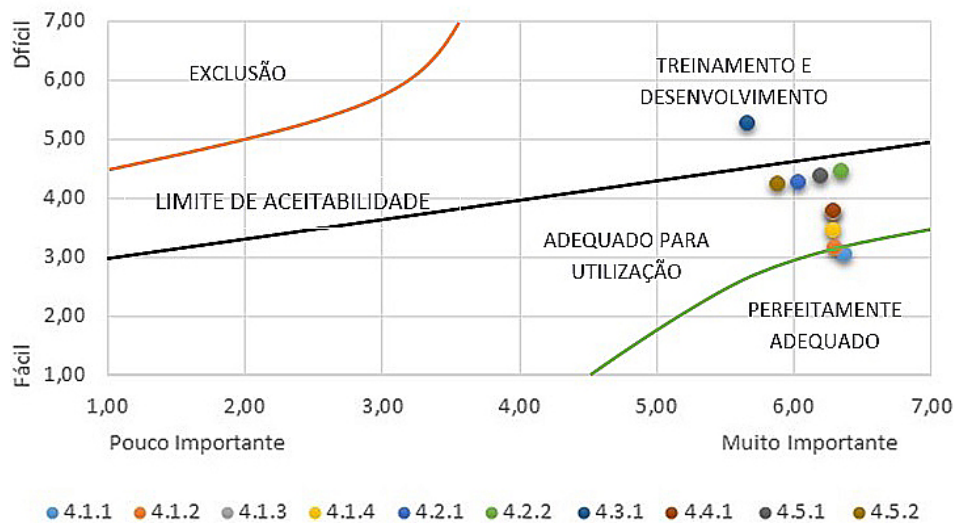

FIGURA 7 - Matriz de Importância x Dificuldade: Dimensão Ambiental

Fonte: Dos autores (2019) 


\section{CONCLUSÕES E CONSIDERAÇÕES FINAIS}

A partir da análise dos indicadores de sustentabilidade empresarial contemplados nos modelos de mensuração utilizados neste estudo, pode-se concluir que são complexos e extensos. Entende-se, que até mesmo as empresas de maior porte possam encontrar dificuldades no preenchimento das informações solicitadas para a elaboração dos indicadores. Em tempo, faz-se necessário mencionar que os modelos são completos e abrangentes, buscando considerar na avaliação da sustentabilidade empresarial todas as variáveis que possam estar relacionadas ao tema. Acredita-se que a utilização de qualquer um destes modelos por micro e pequenas empresas seria inviável diante da necessidade de informações prévias sobre os processos internos da empresa, conhecimentos específicos por parte dos responsáveis e dedicação de tempo para tal finalidade.

Neste sentido, deve-se considerar que a iniciativa desta pesquisa vai ao encontro de uma necessidade das organizações de pequeno porte, uma vez que, contribui para viabilizar a avaliação da sustentabilidade também para este grupo de empreendimentos. O estudo, vinculado ao Programa de Pós-Graduação em Sistemas Ambientais Sustentáveis, concentra-se na sustentabilidade da cadeia produtiva e na eficiência produtiva das agroindústrias. Deste modo, pode-se concluir que o conjunto de indicadores sugerido a partir dos modelos utilizados contribui para avaliação da sustentabilidade destas organizações.

Propor um conjunto de indicadores condizente com a realidade das organizações vai ao encontro das características descritas por Berliner e Brimson (1992) apud Muller (2014, p.87), principalmente as que referenciam a necessidade de utilizar medidores que sejam adaptáveis a necessidade do negócio, eficientes sobre o ponto de vistas dos custos e fáceis de entender a aplicar.

Pode-se concluir que a adaptação realizada na Matriz de Importância x Desempenho de Nigel Slack ficou adequada a avaliação da relação entre a importância do indicador para avaliação da sustentabilidade empresarial e a dificuldade encontrada para obter as informações necessárias à elaboração das informações. Conseguiuse identificar e classificar de maneira adequada as informações da média de cada um dos indicadores e avaliar se estão adequados ou não à utilização.

A partir deste cruzamento das informações utilizando a matriz que relaciona a importância do indicador com seu respectivo grau de dificuldade, identificou-se que a grande maioria dos indicadores sugeridos está apta a utilização. Em tempo, pode-se evidenciar que alguns indicadores que estão próximos ao limite de aceitabilidade demonstrados nas matrizes de avaliação necessitam de ações de melhoria. Estas, podem ser relacionadas à treinamento, desenvolvimento e suporte aos empresários.

Deste modo, tendo como base a avaliação do conjunto de indicadores de sustentabilidade empresarial sugerido a partir do cruzamento e análise dos que são utilizados pelos modelos mencionados no estudo, pode-se considerar que o conjunto está adequado a utilização em micro e pequenas empresas do segmento agroindustrial. Por fim, conclui-se que este trabalho beneficia as organizações empresariais, lhes apresentando um conjunto de indicadores que poderá ser utilizado nas para mensurar a sustentabilidade empresarial. Logo, os benefícios obtidos a partir de práticas de gestão mais sustentáveis serão estendidos aos colaboradores, comunidade local e meio ambiente.

\section{REFERÊNCIAS}

ATKINSON, A. Strategic Performance Measurement and Incentive Compensation. European Management Journal, Dorchester, v. 16, n. 5, p. 552-561, 1998.

BELLEN, H. M. V. Indicadores de Sustentabilidade um levantamento dos principais sistemas de avaliação. Cadernos Ebape, v. 2, n. 1, p. 1-14, mar. 2004.

. Indicadores de Sustentabilidade: uma análise comparativa. 2. ed. Rio de Janeiro: Editora FGV, 2006.

BM\&FBOVESPA. Novo Valor - Sustentabilidade nas Empresas: como começar, quem envolver e o que priorizar. São Paulo, 2016.

BRASIL. Ministério da Indústria Comércio Exterior e Serviços. APL. 2018. Disponível em: http://www.mdic. gov.br/index.php/competitividade-industrial/arranjosprodutivos-locais. Acesso em: 27de jan. 2018.

CARRASQUER, B.; UCHE, J.; MARTÍNEZ-GRACIA, A. A new indicator to estimate the efficiency of water and energy use in agro-industries. Journal of Cleaner Production, Oxford, v. 143, p. 462-473, 2017. 
FEIL, A. A; QUEVEDO, D. M.; SCHREIBER, D. Selection and identification of the indicators for quickly measuring sustainability in micro and small furniture industries. Sustainable Production and Consumption, Uppsala, 3, p. 34-44, 2015.

GAZOLLA, M.; SCHNEIDER, S.; BRUNORI, G. Agroindústrias Familiares: um estudo comparativo entre regiões do Brasil e da Itália. Organizações Rurais \& Agroindustriais, Lavras, v. 20, n. 1, p. 30-48, 2018.

HELlENO, A. L.; MORAES, A. J. I.; SIMON, A. $\mathrm{T}$. Integrating sustainability indicators and Lean Manufacturing to assess manufacturing processes: Application case studies in Brazilian industry. Journal of cleaner production, Oxford, v. 153, p. 405-416, 2017.

IMPERADOR, A. M.; SILVA, M. V. H. Sustentabilidade empresarial: considerações sobre diferentes sistemas de mensuração do desenvolvimento sustentável. HOLOS, Natal, v. 3, p. 429-445, 2018.

INSTITUTO ETHOS DE EMPRESAS E RESPONSABILIDADE SOCIAL. Indicadores Ethos para Negócios Sustentáveis e Responsáveis: Ciclo 2016/2017. São Paulo, 2017.

INSTITUTO ETHOS DE EMPRESAS E RESPONSABILIDADE SOCIAL; SERVIÇO BRASILEIRO DE APOIO ÀS MICRO E PEQUENAS EMPRESAS DO RIO GRANDE DO NORTE (SEBRAE-RN). Indicadores Ethos-Sebrae para Micro e Pequenas Empresas: Diagnóstico de RSE/Sustentabilidade para Pequenos Negócios. São Paulo, 2016.

KOZLOWSKI, A.; SEARCY, C.; BARDECKI, M. Corporate sustainability reporting in the apparel industry: An analysis of indicators disclosed. International Journal of Productivity and Performance Management, Ryerson University, Toronto, Canada, v. 64, n. 3, p. 377-397, 2015.

LEFF, E. Aventuras da epistemologia ambiental. Rio de Janeiro: Editora Garamond, 2004.
MARQUEZ, L. Capitalismo e o Colapso ambiental. Campinas: Editora da Unicamp, 2015.

Miller, G. T.; SPOOLMAN, S. E. Ecologia e Sustentabilidade. 6. ed. São Paulo: Cengage Learning, 2012.

MULLER, C. J. Planejamento estratégico, indicadores e processos: uma integração necessária. São Paulo: Atlas, 2014.

OLIVEIRA, L. R. et al. Sustentabilidade: da evolução dos conceitos à implementação como estratégia nas organizações. Produção, São Paulo, v. 22, n. 1, p. 70$82,2012$.

RAHDARI, A. H.; ROSTAMY, A. A. A. Designing a general set of sustainability indicators at the corporate level. Journal of Cleaner Production, Oxford, V. 108, p. 757-771, 2015.

REVISTA EXAME. Guia Exame de Sustentabilidade. $17^{\mathrm{a}}$ Ed. São Paulo. 2016.

SATOLO, E. G.; SIMON, A. T. Estudo Comparativo dos Modelos de Medição da Sustentabilidade Organizacional. In: Encontro Nacional de Engenharia de Produção, 30, 2010, São Carlos. Anais... São Carlos: ENEGEP, 2010.

SHARMA, V. K.; CHANDNA, P.; BHARDWAJ, A. Green supply chain management related performance indicators in agro industry: A review. Journal of Cleaner Production, Oxford, v. 141, p. 1194-1208, 2017.

SILVA, C. L.; SOUZA-LIMA, J. E. (Orgs). Políticas Públicas e indicadores para o desenvolvimento sustentável. São Paulo: Editora Saraiva, 2010.

SLACK, N. Administração da produção. 8. ed. São Paulo: Atlas, 2018.

ZAMCOPÉ, F. C.; ENSSLIN, L.; ENSSLIN, S. R. Desenvolvimento de um modelo para avaliar a sustentabilidade corporativa. Produção, São Paulo, v. 22, n. 3, p. 477-489, 2012. 